Review

\title{
Present State and Trends of the Geoinformation Industry in China
}

\section{Hui-Feng Zhang ${ }^{1,2}$, Qing-Yun Du ${ }^{1}$ and Chao-Fei Qiao ${ }^{2, *}$}

1 School of Resource and Environmental Science, Wuhan University, 129 Luoyu Road, Wuhan 430079, China; E-Mails: zhanghf@sbsm.gov.cn (H.-F.Z.); qydu@whu.edu.cn (Q.-Y.D.)

2 Development Research Center of National Administration of Surveying, Mapping and Geoinformation of China, 28 Lianhuachixi Road, Beijing 100830, China

* Author to whom correspondence should be addressed; E-Mail: qiaochaofei@163.com; Tel.: +86-10-6388-1536; Fax: +86-10-6388-1541.

Academic Editor: Marc A. Rosen

Received: 28 December 2014 / Accepted: 10 February 2015 / Published: 9 March 2015

\begin{abstract}
The geoinformation industry is a high-tech service industry based on modern surveying and mapping technologies, remote sensing technologies and satellite navigation and positioning technologies. In China, the geoinformation industry is an emerging strategic industry that has rapidly developed; it has played an increasingly important role in the economy and society. This essay briefly introduces the present state of the international geoinformation industry. The state of the geoinformation industry enterprises in China from 2011 to 2013 is introduced. Although this industry has greatly progressed in China, problems and limitations still exist. The structure of the industry is not sustainable. The innovation capacity of Chinese enterprises is weak. Various market demands, increasing social investments, rapid progress in surveying, mapping and geoinformation technology and attention from the government are the main driving factors in this industry. Developing trends in the industry are proposed. Overall, the government will remain the main user of geoinformation applications, and enterprises will continue to merge and reorganize. Mobile geoinformation applications have broad prospects, and new business models will continue to emerge.
\end{abstract}

Keywords: geoinformation industry; surveying and mapping; present state; trend; business model; China 


\section{Introduction}

The geoinformation industry is a high-tech service industry based on modern surveying and mapping technologies, remote sensing technologies and satellite navigation and positioning technologies. Geoinformation industries mainly exploit and utilize geographic information (geoinformation), i.e., the production, processing and application of geographic information [1,2].

The definition or scope of the geoinformation industry varies in different countries and regions. In China, the geographic information system (GIS), Global Navigation Satellite System (GNSS), remote sensing (RS) and surveying and mapping industries are all considered to be sub-industries of the geoinformation industry [1]. However, in the USA, the geoinformation industry is often regarded as being similar to the GIS industry. In India, even the computer-aided design (CAD) industry is defined as belonging to the geoinformation industry [3].

The main aim of the geoinformation industry is to provide geoinformation products and services. Geoinformation products include data, hardware and software and integrated systems. Geoinformation services include providing products, applications and technology. The structure of the geoinformation industry includes geoinformation collection and processing, hardware manufacturing, software programming, application system exploration and geoinformation services [4].

Geoinformation industries have rapidly grown in recent years thanks to the development of information, surveying and mapping technologies and the greater demand for geographic information. In this study, the geoinformation industries in the USA and Europe are briefly introduced. Then, the present state of China's geoinformation industry is presented, and the deficiency of the geoinformation industry in China is analyzed. Finally, the driving factors and developing trends of the geoinformation industry in China are studied.

\section{Basic State of International Geoinformation Industries}

Overall, the geoinformation industry markets in North American and western European countries are larger than those in other countries. The USA market is the largest in the world. The Latin American, eastern European, Middle Eastern and Asia-Pacific markets are booming [4].

Generally, the geoinformation industry can be divided into three sub-industries: the GIS, GNSS and RS industries. Here, the basic states of the international markets for these three industries are introduced.

\subsection{International Markets for GIS Industry}

The GIS industry has developed rapidly in recent years. The statistical data of Daratech Inc., which is a well-known consulting company in the USA, indicates that the growth rate of the global GIS industry was $1 \%$ in 2009 because of the global economic crisis. In contrast, the growth rates in 2007 and 2008 were $17.4 \%$ and $11 \%$, respectively. However, the total output of the global GIS industry market was $\$ 4.4$ billion in 2010, which is $10.3 \%$ larger than that in 2009. In 2011, the total output of the global GIS industry was $\$ 5.0$ billion, which is $8.3 \%$ larger than that in 2010 [5]. 


\subsection{International Market for GNSS Industry}

The GNSS industry has grown rapidly since 2003 and has been the third largest market among the global information technology (IT) industries, following the cellular communication and Internet industries. In 2009, the output of the GNSS industry was $\$ 66$ billion, which is $15 \%$ larger than that in 2008. The location-based service (LBS) market is growing rapidly. By the end of 2014, the output of the global LBS market may be $\$ 1.29$ billion. In 2009, more than 16 million people used LBSs in North America, and this number could potentially exceed 50 million in 2015 [5].

The international market of the global GNSS industry has three characteristics. First, the vehicle navigation market has grown rapidly. The output of the Global Positioning System (GPS) market for cars in 2001 and 2010 was $\$ 3.4$ billion and \$21.9 billion, respectively. Second, the portable navigation devices (PND) market has declined in recent years, because mobile phones with navigation are widely used. Third, the market penetration rate of global mobile phones with navigation has increased. According to a market investigation by the Berg Insight Company, the annual sales revenue of mobile phones with navigation was $\$ 295$ million in 2010, which is $97 \%$ larger than that in 2009 . The anticipated annual sales revenue of mobile phones with navigation in 2015 is $\$ 940$ million. The compound annual growth rate (CAGR) will be $28 \%$ from 2010 to 2015 [5].

\subsection{International Market for the RS Industry}

The global satellite data application market has increased rapidly in recent years. Several thousands of organizations and enterprises in more than 100 countries are engaged in satellite remote sensing applications. The commercialization of remote sensing has been superior in the USA and France compared to in other countries.

\section{Basic State of the Geoinformation Industry in China}

\subsection{Basic State of the Geoinformation Market}

The Chinese economy and society have developed rapidly in recent decades. National infrastructure and informatization result in a tremendous demand for geoinformation. The number of geoinformation projects has increased very quickly. For example, since 2008, digital city construction and construction of the public geoinformation service platform Map World (http://www.tianditu.cn/map/index.html) have led to several billion yuan RMB investments. The First National Geographic Condition Surveying Project, which was launched by the state council and began in March of 2013, had led to a 6.71 billion yuan RMB investment of governments by December 2014. Geoinformation technologies are used in traditional areas, such as fundamental surveying and mapping, city planning, land management and natural resource exploration, and in new areas, such as digital cities, e-government, e-commerce, intelligent transportation and LBS. The main users of geoinformation applications are the government and enterprises. The government has the greatest demand for geoinformation. 


\subsection{Basic State of Geoinformation Enterprises}

Currently, a statistical system for the geoinformation industry has not been set up in China. Because geoinformation industries originated from the surveying and mapping industry, data from the Statistical Yearbook on Surveying and Mapping, which is created by the National Administration of Surveying, Mapping and Geoinformation in China [6-8], are quoted in this study. In this regard, the limitations are clear because the surveying and mapping industry is only a relatively small part of the geoinformation industry. In addition, enterprises that engage with the geoinformation industry in China must obtain surveying and mapping qualifications; therefore, the statistical data used here can indicate the basic state of the geoinformation industry in China.

The annual output of the geoinformation industry in 2011, 2012 and 2013 was 48.736 billion, 54.122 billion and 61.689 billion yuan RMB, respectively. The growth rates in 2012 and 2013 were $11.1 \%$ and $14.0 \%$. The employees in the geoinformation industry numbered 294.5 thousand, 308.5 thousand and 331.9 thousand in these three years. The growth rates in 2012 and 2013 were $4.8 \%$ and $7.6 \%$, respectively. These data show that the geoinformation industry has noticeably developed in China in recent years.

In China, surveying and mapping qualifications include four grades: Grade A, Grade B, Grade C and Grade D. Generally, Grade A enterprises are strongest. The Grade D enterprises are the weakest. The numbers of enterprises that had surveying and mapping qualifications in 2011, 2012 and 2013 were $12,512,13,261$ and 14,040, respectively. Figure 1 illustrates the changes in the numbers of enterprises for each grade over the past three years. The number of enterprises for each of the four grades steadily increased.

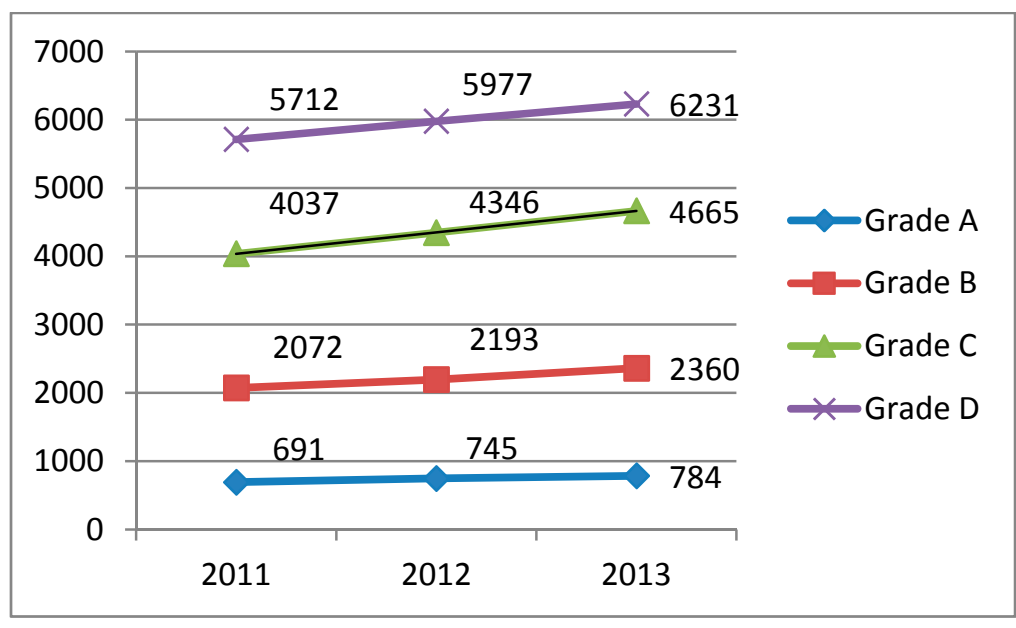

Figure 1. The number of enterprises for each grade in 2011, 2012 and 2013.

Table 1 illustrates the operation of enterprises for each of the four grades by the end of 2013. Although Grade A enterprises represent the smallest among these groups, the annual output of these enterprises accounted for half of the total enterprise output. 
Table 1. Operations of the four grades of enterprises by the end of 2013.

\begin{tabular}{ccccccc}
\hline \multirow{2}{*}{ Qualification } & \multicolumn{2}{c}{ Number of enterprises } & \multicolumn{2}{c}{ Annual output } & \multicolumn{2}{c}{ Employees } \\
\cline { 2 - 7 } & Number & $\begin{array}{c}\text { Proportion } \\
\mathbf{( \% )}\end{array}$ & $\begin{array}{c}\text { Number } \\
\mathbf{( ¥ 1 ~ b i l l o n ) ~}\end{array}$ & $\begin{array}{c}\text { Proportion } \\
\mathbf{( \% )}\end{array}$ & Number & $\begin{array}{c}\text { Proportion } \\
\mathbf{( \% )}\end{array}$ \\
\hline Grade A & 784 & 5.6 & 30.95 & 51.0 & 101,488 & 30.9 \\
Grade B & 2360 & 16.8 & 15.11 & 24.9 & 97,419 & 29.6 \\
Grade C & 4665 & 33.2 & 9.42 & 15.5 & 74,571 & 22.7 \\
Grade D & 6231 & 44.4 & 5.18 & 8.5 & 55,153 & 16.8 \\
\hline
\end{tabular}

According to the Standard of Division of Middle and Small Enterprises in China [9], enterprises with fewer than 300 employees comprise moderate, small and mini enterprises. Among these categories, enterprises with more than 100 employees are defined as moderate enterprises; enterprises with 10-100 employees are defined as small enterprises; and enterprises with fewer than 10 employees are defined as mini enterprises. The data from the 2013 Statistical Yearbook on Surveying and Mapping [8] show that the number of small and mini geoinformation enterprises accounted for $97.0 \%$ of all geoinformation enterprises by the end of 2013. The annual output of small and mini geoinformation enterprises is $¥ 35.8$ billion, which accounts for $59.0 \%$ of the total annual output.

\subsection{State of Sub-Markets}

The GNSS industry has grown rapidly in China in recent years. In 2010, the number of GPS application terminals amounted to 9.083 million, which is $117.8 \%$ higher than the value in 2009 . The number of vehicle-based navigation products sold was 3.427 million, which is $102.2 \%$ higher than the value in 2009. Approximately 5.231 million portable GNSS devices were sold; this value is $148.4 \%$ higher than the value in 2009. With the emergence of intelligent mobile phones with satellite navigation functions, the number of purchased navigation devices has decreased [4]. The Beidou satellite navigation system is a global satellite positioning, navigation and communication system developed by China. In addition to the USA's Global Positioning System (GPS) and Russia's Global Navigation Satellite System (GLONNASS), the Beidou system is the third-most mature satellite navigation system in the world. By the end of 2012, the Beidou system had covered the entire Asia and Pacific region [10]. The annual output of the Beidou navigation industry was more than $¥ 10$ billion in 2013 [11].

The RS industry has developed relatively slowly compared with the GIS and GNSS industries in China. In 2010, the annual output of RS industries was less than ¥3 billion [12], because the number of high-resolution satellites made in China was low. Ziyuan 3, the first surveying and mapping satellite made in China, was successfully launched in January 2012; the spatial resolution of the imagery is $2.5 \mathrm{~m}$. The Gaofen 2 satellite, which has a spatial resolution of less than $1 \mathrm{~m}$, was successfully launched in August 2014 [13].

In the future, additional satellites with high resolutions and multiple functions will be launched.

\subsection{Main Problems of the Geoinformation Industry in China}

Several problems exist regarding the geoinformation industry in China. 
First, the structure of the geoinformation industry is not reasonable. The upstream data collection and downstream geoinformation service are weak compared with those of midstream data processing. Hardware and software are both insufficient for geoinformation data collection. Weaknesses lie in the collection of large-scale imagery, three-dimensional data and the collection speed of geoinformation; thus, the various needs of the economy and society cannot be met. Geoinformation-based value-added services are relatively rare down the industry chain. The depth and extent of services are not sufficient.

The geoinformation enterprises in China are mainly small. A few core enterprises play leading roles. Enterprise groups with strong competitiveness have not emerged, and the structures of the geoinformation products are unbalanced. The types and output of investment products are more abundant than those of consumer products.

In 2011, the National Administration of Surveying, Mapping and Geoinformation of China conducted a sampling survey of 1069 geoinformation enterprises that have Grade A and B surveying and mapping qualifications. The survey indicates that $87 \%$ of geoinformation enterprises have no patents, and a vast majority of enterprises have less than 10 patents [4]. This innovation deficiency leads to homogenization within the geoinformation enterprises. Enterprises lack innovative products, i.e., most products are similar. Middle- and high-grade geoinformation products occupy a small fraction of the international market. Instead of independent innovation, most enterprises are engaged in imitating new technologies and business models.

Since 2010, the Chinese mobile Internet market has grown very quickly [14]. However, the Internet and devices connected to the Internet have not been widely used in geoinformation industries. Successful business models are rare, and advanced technology and equipment have not been widely used by geoinformation enterprises; thus, the needs of society are not met.

Second, Chinese geoinformation enterprises have a lower innovation capability. Innovation capability consists of the ability to create or invent new technologies, products, business models, and so on.

In China, some key technologies are scarce in geoinformation industries. Moving up the geoinformation industry chain, more than $90 \%$ of the satellite remote sensing data used in China are from the USA, France and Canada. Satellite navigation chips have become a major bottleneck to Beidou's industrialization. Approximately $95 \%$ of the market for satellite navigation chips has been occupied by the USA. Most domestic enterprises do not have the ability to develop multi-mode navigation chips [4].

In the middle of the geoinformation industry chain, core remote sensing processing software, which has its own intellectual property rights, is nearly non-existent in China. The research and development of processing, management, analysis, expression and visualization technologies for massive and multi-source geoinformation data are insufficient.

The integrated service of geoinformation should be strengthened down the geoinformation industry chain. Geoinformation web services and LBS business models should be proposed.

The third author with his colleagues conducted a survey on the state of technological innovation in 54 randomly chosen Chinese geoinformation enterprises in 2012 [15]. The survey indicates the following conclusions. First, the innovation capabilities of large enterprises are better than those of small and micro enterprises. The reason for this finding is that, relative to small and micro enterprises, large enterprises have more researchers and can also invest more money in technological innovation. Second, market demand is the most important factor driving innovation. When asked about the driving 
factors of innovation, $65 \%$ of enterprises chose "market demand", $21 \%$ chose "scientific and technological development", $8 \%$ chose "government support" and 6\% chose "pressure from competitors". Third, there are different styles of technological innovation. When asked about innovation paths, $46 \%$ of enterprises chose "introduce-digest-absorb-re-innovate", 44\% chose "original innovation" and 10\% chose "integration innovation".

The main problems faced by innovative enterprises are the following. First, the overall level of innovation is low. From 2009 to 2011, only $48 \%$ of enterprises invested in new products; $37 \%$ invested in new process; and 35\% obtained patents. Second, the external environment for innovation is not good. The survey indicates that only $24 \%$ of enterprises have obtained investments through government funding and only $9 \%$ have obtained loans from financial institutions. Financing inconvenience is a common problem encountered by these enterprises. Third, most enterprises pay more attention to technological innovation than mechanism innovation. However, mechanism innovation, such as administrative or business model innovation, is often more important than technological innovation.

Finally, Chinese geoinformation enterprises are behind international competition.

The geoinformation market is open to foreign companies. However, foreign companies must obey Chinese laws and regulations. Because some geoinformation data, such as the coordinates of military facilities, are very crucial to national security, the geoinformation data used by foreign companies must be strictly examined before use, such that data that are crucial to national security can be removed.

In recent years, the West has occupied an important place in the international market regarding web image services, navigation and positioning products by virtue of its technological superiority regarding satellite navigation and positioning, high-resolution satellites, digital video, high-grade survey instrumentation and large geographic information systems. The civilian navigation and positioning market and high-resolution satellite data in China have been dominated by products from the USA and France. The advanced survey instrument market in China has been dominated by the USA, Japan, Switzerland and other countries. Transnational corporations, such as Google and Microsoft, have established global business chains with geoinformation services. The competition between these companies is intense. In contrast, many geoinformation enterprises in China are generally small enterprises. Few geoinformation enterprises in China attain annual productions of $¥ 2$ billion.

\section{Driving Factors of the Geoinformation Industry in China}

\subsection{Various Market Demands}

The Chinese economy has developed steadily and rapidly over the past two decades and has facilitated the rapid development of the geoinformation industry in China. Domestic consumption has been stable, and the income of residents has continually increased. Enterprises have a strong desire to invest.

In recent years, the development of Internet geoinformation services, mobile phone map services, vehicular navigation devices and LBSs has greatly broadened consumers' knowledge of the value of geoinformation. With the application of geoinformation technologies in the industry, the government and enterprise consumers are profoundly realizing the economic, social and environmental benefits created by geoinformation applications. In the processes of ecological civilization construction, urbanization and the updating of infrastructure, such as railways, roads and airports, diverse maps 
represent important fundamental materials. The demands of various professions for geoinformation are more explicit.

China is transitioning from an industrial society to an information society [16]. The mobile Internet market boomed in 2013. According to a report provided by Gartner Inc., which is a market research and consultation company, the number of mobile phone consumers in China has now reached more than one billion. China has become the world's largest market for intelligent terminals [17]. By the end of December, 2013, the number of Chinese netizens was 618 million, and Internet penetration was 45.8\%. The number of mobile phone consumers has reached 500 million, and it continues to increase [18]. Mobile phone-based e-commerce applications have rapidly developed. The number of mobile online payment consumers accounts for $25.1 \%$ of the total number of mobile phone consumers [19].

In 2013, the numbers of automobiles produced and sold in China were 22.1168 million and 21.9841 million, respectively. The numbers of passenger cars produced and sold were 18.0852 million and 17.9289 million, respectively. This was the first year that the number of automobiles produced and sold in China exceeded 20 million, ranking the highest in the world for five consecutive years [20]. Since 2010, the telematics industry has developed quickly in China. Telematics refer to comprehensive systems, in which wireless voice, digital communication and satellite navigation and positioning systems are used to provide drivers and passengers with various services, such as navigation and positioning, communication, traffic information and even entertainment [21]. Road map and satellite navigation and positioning systems play very important roles in telematics. The continuing growth of the automobile and telematics markets facilitates the expansion of the geoinformation market.

\subsection{Increasing Social Investment}

More than 10 Chinese geoinformation companies entered the stock market in the past decade, indicating that geoinformation industries have gained the attention of the capital market and have entered into a new stage with more rapid development.

With the continuous generation of new geoinformation applications and services, Internet search companies, e-commerce providers, communication service providers and automobile manufacturers have entered into the geoinformation market. These companies include Baidu, Huawei, China Mobile and Alibaba, creating new market opportunities for the development of geoinformation industries.

\subsection{Rapid Progress in Surveying, Mapping and Geoinformation Technology}

With the rapid development of network technology, information technology, computer technology, sensor technology and other related fields, the development of surveying, mapping and geoinformation technology is becoming increasingly integrated and informatized.

At present, big data technology has gradually penetrated all aspects of industry. The combination of big data and LBS improves the accuracy of marketing. More consumers read the news, watch videos, enjoy entertainment and shop on the mobile Internet. Effective advertisements are provided to consumers by virtue of multi-level classification based on peripheral information on the consumers' location, such as catering, training, entertainment, shopping and other information. Personalized services are given to different consumers who have various needs [22]. 
Cloud computing is changing the commercial operation of geoinformation industries. At present, some international companies, such as Google, and domestic companies are implementing geoinformation cloud service plans. In the near future, geoinformation application patterns will greatly change with the emergence of new products related to cloud computing.

Geodesy is changing from a static to dynamic state, from ground-based to space-based and from regional to global. Positioning accuracy is improving significantly. Geodesy's applications are continually increasing. The GNSS has rapidly progressed over the years. Multiple systems with interoperability have become the mainstream applications for GNSS [23].

The developing trends in aerial and aerospace remote sensing are "three-multi", i.e., multi-sensor, multi-platform and multi-angle, and "four-high", i.e., high spatial resolution, high spectral resolution, high phase resolution and high radiative resolution. More satellites can be used in the fields of surveying, mapping and geoinformation. Aerial remote sensing, unmanned aerial vehicles (UAV), car-mounted mobile remote sensing and underwater scanning are progressing [23].

The developing trends in geoinformation processing and management are automation and intelligence. Three-dimensional spatial data management is becoming a research hotspot. GIS solutions that are based on grid computing and cloud computing are constantly emerging. Major changes have occurred in the management of massive spatial data. Three-dimensional spatial data management has become a primary focus [23].

Geoinformation services are developing broader coverage, flexibility and relations with the Internet. The development of new technologies, such as those connected to the Internet, supports easily accessible and intelligent geoinformation services [23].

\subsection{Attention from the Government}

In January 2014, "The report of the General Office of the State Council on promoting the development of the geoinformation industry" was issued. The report proposed the guiding ideology, basic principles, main goals, key areas and relative policies of promoting geoinformation industries in the future. In this report, geoinformation industries are defined as emerging strategic industries for the first time [1]. In July 2014, China's National Development and Reform Commission and the National Administration of Surveying, Mapping and Geoinformation jointly issued the "National Geoinformation Industry Development Plan (2014-2020)" [24]. The first fund in China for supporting geoinformation enterprises was founded in August, 2014 [25].

The National Administration of Surveying, Mapping and Geoinformation of China (NASG) is the official department responsible for the administration of the Chinese geoinformation industry. Because much of the fundamental geoinformation, such as national geographic maps at the scales of 1:10 thousand and 1:50 thousand, is crucial to national security, these fundamental types of geoinformation are confidential in China. However, these types of fundamental geoinformation may be broadly used in many fields. Therefore, NASG is engaged in revising relevant policies, such that more confidential fundamental geoinformation can be used by the public. 


\section{Development Trends in China's Geoinformation Industry}

\subsection{Government as the Main User of Geoinformation Applications}

The government, enterprises and the public are the three main users of geoinformation applications. The government is the main user of most large geoinformation projects.

Digital city construction and public geoinformation services strongly influence the development of the geoinformation industry. Since 2006, all 333 cities and more than 380 counties in China have engaged in digital city constructions. By the end of 2014, more than 220 cities and more than 100 counties have finished digital city constructions, and more than 3,600 applications have been developed. By the end of 2015, digital cities for all 333 cities and some counties in China will be completed [26].

In China, more than ten government departments are engaged in promoting smart city construction. These departments include the Ministry of Industry and Information Technology, the Ministry of Science and Technology, the Ministry of Housing and Urban-Rural Development, the National Administration of Surveying, Mapping and Geoinformation and the Chinese Academy of Engineering. The main projects of these departments include developing technologies, setting standards and conducting experiments. Since 2011, the Ministry of Industry and Information Technology has issued more than 10 smart city plans. The Ministry of Housing and Urban-Rural Development has selected 193 cities as experiment units for national smart city construction. The National Administration of Surveying, Mapping and Geoinformation selected nine cities (e.g., Taiyuan, Linyi and Xuzhou) as experiment units for smart city construction. The Chinese Academy of Engineering selected several cities as experiment units, such as Beijing, Wuhan, Hangzhou and Ningbo. Smart city applications include environmental protection, medicine and health, petrochemicals, transportation, security, government affairs, community and education. [27].

\subsection{Merging and Reorganization of Enterprises}

The potential of geoinformation industries has been apparent since the early 21 st century. Some international IT companies began to join these industries. Since 2005, some international IT companies have purchased traditional geoinformation enterprises to obtain spatial data resources and core geoinformation technologies to enter the geoinformation market. These purchases enhanced their ability to provide products and services in geoinformation areas, and the results of these mergers and purchases produced geographic products and core technologies [4]. For example, in 2005, Hexagon, the world-leading supplier of survey systems, purchased Leica Geosystems Inc., which has a 180-year history. In 2010, Hexagon purchased the GIS software company, Intergraph Inc. The market share of the latter company was less than that of the Environmental Systems Research Institute Inc. (ESRI), which is the largest GIS software company in the world [28]. In 2013, Google Inc. purchased the navigation software company, WAZE, for 1.1 billion dollars [29].

In May 2014, Tencent Inc., the largest instant messaging company in China, purchased $11.28 \%$ of the stock rights of Navinfo Inc., which is one of the two largest navigation map companies in China [30]. In July 2014, Autonavi Inc., the other large navigation map company, was purchased by the Alibaba Group, which is the largest e-business company in China [31]. 


\subsection{Broad Prospects of Mobile Geoinformation Applications}

Mobile Internet comprises the Internet and the service through which the mobile network is used as the accessing network [32]. Mobile Internet users can use browser-based Internet services, from a handheld mobile device, such as a smartphone or feature phone, to access to the World Wide Web. China has the largest number of mobile users in the world. The increase in smart mobile phone utilization and third generation $(3 \mathrm{G})$ network coverage and the decrease in the price of using the Internet led to the rapid growth of mobile web access [33].

Mobile Internet access has greatly changed how people receive messages. With the main Internet service companies, such as Alibaba, Baidu and Tencent, entering the LBS industry, this industry has great opportunities for development.

\subsection{New, Constantly Emerging Business Models}

A business model describes the rationale of how an organization creates, delivers and captures value in economic, social, cultural or other contexts. The process of business model construction is part of the business strategy [34].

Business model innovation may create economic benefits. The key factor of business model innovation is an enterprise's ability to rapidly respond to consumers' needs and integrate various resources. Currently, many geoinformation enterprises in China are transforming into service innovation-oriented enterprises. One-stop services are provided based on customers' needs, which will create new business models [35].

For example, the demand for high-resolution images will change in the future. Professional or commercial consumers would begin to purchase image services rather than images. Additionally, digital navigation map products with bi-directional communication functions will be developed with the improvement of fourth generation (4G) networks.

\section{Conclusions}

Geoinformation industries are one type of emerging strategic industry with great development potential [1]. These emerging geoinformation industries have the following characteristics: broad service fields, little resource consumption, no environmental pollution, many job opportunities, high added value and good comprehensive benefits. Promoting geoinformation industries is necessary for China to overtake international competition and to construct modern industrial systems.

This study analyzed the present state of geoinformation industries in China. In addition, the geoinformation industries in other countries were briefly introduced. Overall, the geoinformation industry in China is a potential source of economic growth.

\section{Author Contributions}

Hui-Feng Zhang, Qing-Yun $\mathrm{Du}$ and Chao-Fei Qiao equally contributed to this research. Specifically, Qing-Yun Du presented the research concept; Hui-Feng Zhang organized the content; and Chao-Fei Qiao collected the primary resources. 


\section{Conflicts of Interest}

The authors declare no conflict of interest.

\section{References}

1. General Office of China State Council. General Office of China State Council issued suggestion on promoting the development of geoinformation industry, 2014. Available online: http://www.chinanews.com/gn/2014/01-30/5800620.shtml (accessed on 19 December 2014). (In Chinese)

2. Qiao, C.F. Definition, Classification and Statistical Index of Geospatial Industry. Geomat. World 2012, 10, 36-39. (In Chinese)

3. Research and Markets. GIS Market in India 2012-2016, 2013. Available online: http://www.researchandmarkets.com/research/59nbxg/gis_market_in (accessed on 19 December 2014).

4. Xu, Y.Q.; Liu, L. Report on status of Geographic Information Industry in China in 2011. In Report on Status of Geographic Information Industry in China (2011), 1st ed.; Xu, D.M., Wang, C.F., Bai, Y.S., Eds.; Social Sciences Academic Press: Beijing, China, 2011; pp. 1-47. (In Chinese)

5. Qiao, C.F.; Sun, W. Status and Trends of Geographic Information Industry Abroad. In Report on Status of Geographic Information Industry in China (2011), 1st ed.; Xu, D.M., Wang, C.F., Bai, Y.S., Eds.; Social Sciences Academic Press: Beijing, China, 2011; pp. 261-267. (In Chinese)

6. The National Administration of Surveying, Mapping and Geoinformation of China. China Surveying, Mapping and Geoinformation Yearbook (2011); Surveying and Mapping Press: Beijing, China. (In Chinese)

7. The National Administration of Surveying, Mapping and Geoinformation of China. China Surveying, Mapping and Geoinformation Yearbook (2012); Surveying and Mapping Press: Beijing, China. (In Chinese)

8. The National Administration of Surveying, Mapping and Geoinformation of China. China Surveying, Mapping and Geoinformation Yearbook (2013); Surveying and Mapping Press: Beijing, China. (In Chinese)

9. Ministry of Industry and Information. Standard of Division of Middle and Small Enterprises in China, 2011. Available online: http://www.miit.gov.cn/n11293472/n11293832/n11293907/ n11368223/13912671.html (accessed on 19 December 2014). (In Chinese)

10. China Beidou began providing positioning, navigation and timing service. Available online: http://news.xinhuanet.com/mil/2011-12/27/c_122493462.htm (accessed on 19 December 2014). (In Chinese)

11. Output value of Beidou navigation industry exceeds 10 billion yuan RMB. Available online: http://news.xinhuanet.com/2014-09/11/c_1112448283.htm (accessed on 19 December 2014). (In Chinese) 
12. Annual report on Development of Remote Sensing Industry in China (2010-2011). Available online: http://wenku.baidu.com/link?url=6R01AQDRN88X5wyc0FLRUfJuGGbv0L7Z230RXNsurtLMZEfVXBGwbDJXhDQoHH78AmPnY9o_KyTg-H_JSc1la1Bca4IbaShxN6vWSss3mu (accessed on 19 December 2014). (In Chinese)

13. China launched Gaofen 2nd satellite. Available online: http://world.people.com.cn/n/2014/0819/ c157278-25495629.html (accessed on 19 December 2014). (In Chinese)

14. Ye, H. First year of Mobile Internet in China? Telecom World 2010, 12, 4. (In Chinese)

15. Sun, W.; Qiao, C.F. Investigation and Analysis of Science and Technology Innovation of Geospatial Organizations. Bull. Surv. Mapp. 2014, 2, 131-134. (In Chinese)

16. Zhang, X.H. Analysis of Chinese information society development. In Marginal revolution 2.0: Report on Information Society, 1st ed.; 50 Persons Forum on Information Society, Eds.; Shanghai Far East Press: Shanghai, China, 2013; p. 45. (In Chinese)

17. DinK. ZDC: Annual report on Mobile Phone Market in China (2013-2014). Available online: http://www.199it.com/archives/203469.html (accessed on 19 December 2014). (In Chinese)

18. DinK. CNNIC: 33rd Statistical Report on Development of Chinese Internet Network in 2014, Chapter of netizens. Available online: http://www.199it.com/archives/187745.html (accessed on 19 December 2014). (In Chinese)

19. Monitoring and Coordination Bureau. Statistical Bulletin of Communication operation industry in 2013 in China, 2014. Available online: http://www.miit.gov.cn/n11293472/n11293832/n11294132/ n12858447/15861120.html (accessed on 19 December 2014). (In Chinese)

20. Chinese automobile annual sales exceed 20 million in first time in 2013. Available online: http://www.ccn.com.cn/news/yaowen/2014/0109/526214.html (accessed on 19 December 2014). (In Chinese)

21. Hu, H.M. Present state and trend of telematics. China Economic Times, 8 July 2014.

22. Qiao, C.F. Big Data and It's for Surveying, Mapping and Geoinformation Industry. Bull. Sur. Mapp. 2013, 1, 107-109. (In Chinese)

23. Li, P.D. The development of science and technology innovation of surveying, mapping and geoinformation in China. In Report on Status of Innovation of Surveying \& Mapping \& Geographic Information in China (2012), 1st ed.; Xu, D.M., Wang, C.F., Zhang, H.F., Eds.; Social Sciences Academic Press: Beijing, China, 2013; pp. 58-72. (In Chinese)

24. National Development and Reform Commission. Notification on issue of National Geoinformation Industry Development Plan (2014-2020) by National Development and Reform Commission, and National Administration of Surveying, Mapping and Geoinformation. Available online: http://www.sdpc.gov.cn/gzdt/201408/t20140805_621333.html (accessed on 19 December 2014). (In Chinese)

25. National Administration of Surveying, Mapping and Geoinformation. The first fund in China for supporting geoinformation enterprises was founded. Available online: http://www.sbsm.gov.cn/ article/chyw/201408/20140800015943.shtml (accessed on 19 December 2014). (In Chinese)

26. National Administration of Surveying, Mapping and Geoinformation. Conference on transformation from digital city to smart city. Available online: http://www.sbsm.gov.cn/ article/chyw/201412/20141200020170.shtml (accessed on 19 December 2014). (In Chinese) 
27. Xu, Y.Q.; Ning, N.Y.; Xiong, W.; Liu, L.; Gui, D.Z. Report on Geospatial Intelligent System of Smart China. In Report on Geospatial Intelligent System of Smart China (2013), 1st ed.; Xu, D.M., Wang, C.F., Zhang, H.F., Eds.; Social Sciences Academic Press: Beijing, China, 2013; p. 15. (In Chinese)

28. Development Research Center of National Administration of Surveying, Mapping and Geoinformation of China. Available online: http:/fazhan.sbsm.gov.cn/article/zlyzcyj/ 201110/20111000092707.shtml (accessed on 19 December 2014). (In Chinese)

29. Google spent $\$ 1.1$ billion on purchasing Waze which is a navigation software company. Available online: http://news.xinhuanet.com/fortune/2013-06/13/c_124847545.htm (accessed on 19 December 2014). (In Chinese)

30. Tencent Inc. purchased $11.28 \%$ stock rights of Navinfo Inc. Available online: http://money.163.com/14/0521/22/9SQ7DJIN00253B0H.html (accessed on 19 December 2014). (In Chinese)

31. Alibaba will spend $\$ 1.1$ billion to purchase Autonavi Inc. www.chinanews.com. Available online: http://finance.chinanews.com/it/2014/02-10/5820085.shtml (accessed on 19 December 2014). (In Chinese)

32. Wen, J.; Zhang, S.F.; Li, T.Z. Overview on Developing Status Quo and Trend of Mobile Internet Technology. Commun. Technol. 2014, 47, 977-984. (In Chinese)

33. Yang, D.L. The Study about the Trend of Mobile Web Development. Comput. Knowl. Technol. 2012, 8, 1039-1042. (In Chinese)

34. Wikipedia. Business Model. Available online: http://en.wikipedia.org/wiki/Business_model (accessed on 19 December 2014).

35. Sun, B. Some Thoughts of Business Model Innovation of Geographic Information Industry. In Report on Status of Geographic Information Industry in China (2011), 1st ed.; Xu, D.M., Wang, C.F., Bai, Y.S., Eds.; Social Sciences Academic Press: Beijing, China, 2011; pp. 153-165. (In Chinese)

(C) 2015 by the authors; licensee MDPI, Basel, Switzerland. This article is an open access article distributed under the terms and conditions of the Creative Commons Attribution license (http://creativecommons.org/licenses/by/4.0/). 